\title{
Theoretical Foundations and Technological Capabilities of Hydrocarbonyl Process while Recovering Copper from Technogenic Wastes
}

\author{
Igor V. Fedoseev' ${ }^{1}$ Mikhail Sh. Barkan', Anton B. Kornev' ${ }^{1}$ Aleksandr S. Danilov ${ }^{1 *}$ \\ 1 Geoecology Department, Saint-Petersburg Mining University, 21 $1^{\text {st }}$ Line 2, Saint-Petersburg, 199106, Russia \\ * Corresponding author's e-mail: aleksandrsdanilov@gmail.com
}

\begin{abstract}
Secondary processing of waste from metallurgical and other industries becomes an urgent issue in the face of increasing anthropogenic pressure and a shortage of sources of materials. The paper shows the results of chemical and technological studies of processes, executing in the $\mathrm{Cu}(\mathrm{II})-\mathrm{Cu}(\mathrm{I})-\mathrm{Cl}^{-}-\mathrm{CO}-\mathrm{H}_{2} \mathrm{O}$ system. The processing technology of copper-bearing intermediate products multicomponent leaching solutions, permitting high purity copper production at the least economic cost, is proposed.
\end{abstract}

Keywords: polymetallic sulphide ores, high purity copper, hydrocarbonyl process, reduction ratio, producer gas.

\section{INTRODUCTION}

The main copper raw materials in the world are polymetallic sulphides, the processing of which is carried out mostly by pyrometallurgical processes. However, this technology has some drawbacks, the analysis of which is considered in the paper [Mushkatin, 2009].

Despite the prevalence of pyrometallurgical processes, the global copper production by implementing hydrometallurgical approach increases. The development works for this research trend are actively conducted both abroad [Schlesinger et al., 2011; Lundstrom et al., 2005] and in Russia [Tcapakh et al.,2012; Khomchenko et al., 2014; Altushkin et al., 2017].

Thus, "Outotec" company developed the hydrometallurgical processing technology of copper ore polymetallic sulphide concentrate with the following composition, in \%: $\mathrm{Cu}-29.6 ; \mathrm{Fe}$ $-30.6 ; \mathrm{Zn}-2.18 ; \mathrm{Pb}-0.38 ; \mathrm{S}-33.4$. The concentrate is subjected to leaching by the $\mathrm{Cu}$ (II) - $\mathrm{Cu}(\mathrm{I})-\mathrm{Cl}^{-}(\mathrm{NaCl})-\mathrm{O}_{2}$ solution at the atmospheric pressure and a temperature of $95^{\circ} \mathrm{C}$ in five consecutive reactors. The copper and iron leaching occurs in line with the following formulas [Valkamak, 2013]:

$$
\begin{gathered}
\mathrm{CuFeS}_{2}(s)+3 \mathrm{Cu}^{+2}(\text { aq. }) \rightarrow 4 C u^{+}(\text {aq. })+ \\
+\mathrm{Fe}^{+2}(\text { aq. })+2 S^{0}(s) \\
4 \mathrm{Cu}^{+}(a q .)+\mathrm{O}_{2}(g)+4 H^{+}(a q .) \rightarrow \\
\rightarrow 4 C u^{+2}(a q .)+4 \mathrm{H}_{2} \mathrm{O}(a q)
\end{gathered}
$$

In the process of leaching, iron precipitates at the expense of hydrolysis with acid regeneration in accordance with the reaction (1), which takes part in copper (I) oxidation according to formulas (2). Recovery to solution is as follows, in \%: $\mathrm{Cu}>95 ; \mathrm{Ag}-93-94: \mathrm{Zn}>97$.

The obtained solution is subjected to 3-stage extraction with subsequent 2-stage washing and 2 -stage re-extraction. As a result of extraction, the pure $\mathrm{CuSO}_{4}$ electrolyte with copper content $\sim 50$ $\mathrm{g} / \mathrm{l}$, by $\sim 20 \mathrm{mg}$ of $\mathrm{Zn}^{+2}$ and $\mathrm{Fe}^{+2}$ and $\sim 10 \mathrm{mg} / \mathrm{l} \mathrm{Cl}$ - is obtained. This solution is sent to electrolysis with insoluble anode. The process is conducted up to $\mathrm{Cu}$ (II) impoverishment to $35 \mathrm{~g} / 1$ with $\mathrm{H}_{2} \mathrm{SO}_{4}$ concentration increase up to $180 \mathrm{~g} / \mathrm{l}$. As a result, the LME A grade cathode copper is obtained.

However, the hydrometallurgical copper production also has some drawbacks: insufficient 
$\mathrm{CuSO}_{4}$ electrolyte purification; high specific electricity consumption during the electrolysis with insoluble anodes; the necessity of copper (II) transition from oxide to sulphate form when leaching sulphide copper concentrates. This stipulates the interest in the alternative chemical method of pure copper production, the advantage of which is the possibility of cost-effective commercial isolation of its high-purity compound from multicomponent solutions resulting from concentrates and intermediate product leaching. The technology proposed by the "Outotec" company developers includes: oxidation leaching of sulphide concentrate by $\mathrm{Cu}(\mathrm{II})-\mathrm{Cu}(\mathrm{I})-\mathrm{Cl}_{2}-\mathrm{NaCl}$ solution; four-stage purification of the obtained multicomponent chloride-sulphate solution from impure metals ( $\mathrm{Zn}, \mathrm{Ni}, \mathrm{Pb}$ and others) and sulphate-ions; obtaining of copper (I) oxide $-\mathrm{Cu}_{2} \mathrm{O}$ from copper (I) chloride solution, obtaining of copper powder as a result of copper (I) oxide reduction by hydrogen in conveyor furnace at a temperature of $650-800^{\circ} \mathrm{C}$ [Haavanlammi et al., 2011].

These technology solutions cannot be acknowledged as fully successful because of the large number of process stages, but copper (I) chloride is undoubtedly worth noticing by process engineers as an intermediate product in the processing chain of high-purity copper chemical production.

\section{METHODS}

The technological capabilities of copper (I) chloride are determined by the aggregate of its physicochemical properties, such as:

- good extractability of chloro complex $\mathrm{CuCl}_{2}$ by solvents and reagents;

- the possibility of $\mathrm{CuCl}$ purification by recrystallization from $\mathrm{NaCl}$ solution;

- direct copper production from $\mathrm{CuCl}$ by the effect of producer gas, containing $\mathrm{CO}$ and $\mathrm{H}_{2}$ at the expense of the following process:

$$
\mathrm{CuCl} \rightarrow \mid \begin{array}{ll}
\stackrel{+\mathrm{CO}, \mathrm{H}_{2} \mathrm{O}}{\longrightarrow} & \mathrm{Cu}+\mathrm{HCl}+\mathrm{CO}_{2} \\
+\mathrm{H}_{2} & \mathrm{Cu}+\mathrm{HCl}
\end{array}
$$

- hydrolytic decomposition under the influence of water or steam:

$$
2 \mathrm{CuCl}+\mathrm{H}_{2} \mathrm{O} \rightarrow \mathrm{Cu}_{2} \mathrm{O}+2 \mathrm{HCl}
$$

The resulting copper (I) oxide is a technologically convenient product for obtaining both pure electrolyte and for its regeneration after electrolysis with insoluble anode at the expense of the following reaction:

$$
\mathrm{Cu}_{2} \mathrm{O}+\frac{1}{2} \mathrm{O}_{2}+2 \mathrm{H}_{2} \mathrm{SO}_{4}=2 \mathrm{CuSO}_{4}+2 \mathrm{H}_{2} \mathrm{O}
$$

Thereby, the aggregate of copper (I) chloride physicochemical properties permits using this compound for the development of hydrometallurgical technology for copper production from its concentrates and intermediate products with the use of both chemical and electrochemical reduction. The main stage should be the technologically and economically effective process of pure copper (I) chloride recovery from multicomponent solutions, based on copper (II) reduction to copper (I) by $\mathrm{CO}$ effect with the relevant pressure [Fedoseev 2012, 2016].

\section{RESULTS}

Let us consider the theoretical basis for the hydrocarbonyl process of copper (II) reduction to copper (I) in the $\mathrm{Cu}(\mathrm{II})-\mathrm{Cu}(\mathrm{I})-\mathrm{Cl}^{-}-\mathrm{CO}-\mathrm{H}_{2} \mathrm{O}$ system.

Carbon monoxide is thermodynamically capable of reducing $\mathrm{Cu}$ (II) to $\mathrm{Cu}$ (I) and $\mathrm{Cu}(0)$. This way, for the following reactions:

$$
\begin{aligned}
& 2 \mathrm{Cu}^{2+}+\mathrm{CO}+\mathrm{H}_{2} \mathrm{O} \rightarrow 2 \mathrm{Cu}^{2+}+\mathrm{CO}_{2}+2 \mathrm{H}^{+} \\
& \Delta G^{\circ}=-24 \mathrm{~kJ} \\
& \mathrm{Cu}^{2+}+\mathrm{CO}+\mathrm{H}_{2} \mathrm{O} \rightarrow \mathrm{Cu}^{\circ}+\mathrm{CO}_{2}+2 \mathrm{H}^{+} \\
& \Delta G^{\circ}=-85 \mathrm{~kJ}
\end{aligned}
$$

Nevertheless, these procedures are not executed under normal conditions because of the high carbon-oxygen bond strength in the $\mathrm{CO}$ molecule. The reaction (6) turned out to be successful only at the CO pressure of 10-40 atm and $\mathrm{t}=160-190^{\circ} \mathrm{C}$ from the $\mathrm{CuSO}_{4}$ solution. In the $\mathrm{Cu}(\mathrm{II})-\mathrm{Cl}^{-}$solution, the reaction (6) may execute at gas room temperature and under the atmospheric pressure, if a small amount of palladium (II) chloride is introduced. The kinetic curve of $\mathrm{Cu}(\mathrm{II}) \rightarrow \mathrm{Cu}(\mathrm{I})$ reduction process is shown in Figure 1. Solution composition is: $[\mathrm{Pd}(\mathrm{II})]=$ $5 \mathrm{mg} / \mathrm{l} ;[\mathrm{CuCl} 2]=0.826 \mathrm{M} ;[\mathrm{HCl}]=1.2 \mathrm{M}$. On the 


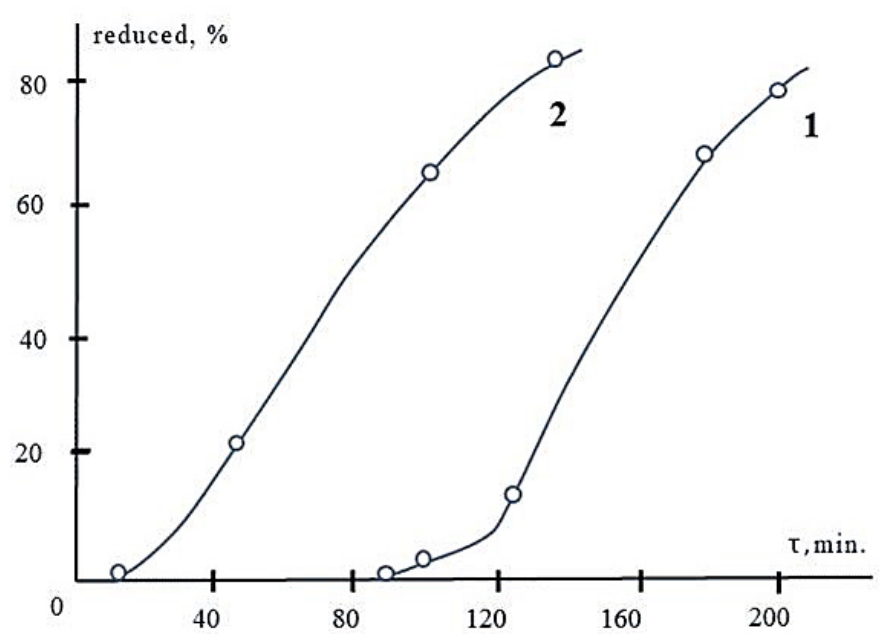

Fig. 1. Kinetic curves of $\mathrm{Cu}(\mathrm{II}) \rightarrow \mathrm{Cu}(\mathrm{I})$ reduction process by carbon monoxide in the presence of palladium (II). 1 - without $\mathrm{CuCl}$ nucleant; 2 - with $\mathrm{CuCl}$ nucleant.

other hand, the processing conditions are as follows: $\mathrm{t}=19^{\circ} \mathrm{C}$; $\mathrm{PCO}-$ atmospheric.

A rather lengthy period of reduction process induction, which shortens when introducing copper (I) chloride to the initial solution, should be noted.

In order to determine the copper (II) reduction process, the mechanism in the $\mathrm{Cu}(\mathrm{II})-\mathrm{Cu}(\mathrm{I})$ $-\mathrm{Cl}^{-}-\mathrm{CO}-\mathrm{H}_{2} \mathrm{O}$ system, the tests pertaining to the influence of the $[\mathrm{Cu}(\mathrm{I})]:[\mathrm{Cu}(\mathrm{II})]$ ratio on copper (II) reduction ratio to copper (I) (Fig. 2) and the value of light absorption in $\mathrm{Cu}(\mathrm{II})-\mathrm{Cu}(\mathrm{I})$ isomolar solutions (Fig. 3) were conducted.

The composition of initial solution is: $[\mathrm{Cu}(\mathrm{II})]=20 \mathrm{~g} / \mathrm{l} ;[\mathrm{HCl}]=3 \mathrm{M}$; The processing conditions are as follows: $\mathrm{t}=50^{\circ} \mathrm{C}$; $\mathrm{PCO}-$ atmospheric. The highest values of $\mathrm{Cu}$ (II) $\rightarrow \mathrm{Cu}$ (I) reduction ratios and light absorption in $\mathrm{Cu}$ (II) - $\mathrm{Cu}(\mathrm{I})$ isomolar solutions are observed at the $[\mathrm{Cu}(\mathrm{I})]:[\mathrm{Cu}(\mathrm{II})]$ ratios of $1: 2$ and $1: 1$. The copper (I) function in the copper (II) reduction mechanism is associated with the fact that its chloro complex - $\mathrm{CuCl} 2$ - interacts with $\mathrm{CO}$ molecules quickly, forming carbonyl chloride anions with $\mathrm{CuI}(\mathrm{CO}) n$ cations, where $\mathrm{n}=1-3$. The latter reacts with copper (II) ions and forms the intermediates with CO-bridge bond between the $\mathrm{Cu}(\mathrm{I})$ and $\mathrm{Cu}$ (II) ions: $\mathrm{CuI}(\mathrm{CO}) \mathrm{CuII}$ and $\mathrm{CuI}(\mathrm{CO}) 2 \mathrm{Cu} 2 \mathrm{II}$. Under the influence of water in these intermediates, the intraspheric redox process takes place:

$$
\begin{aligned}
& \mathrm{CO}+\mathrm{H}_{2} \mathrm{O}=\mathrm{CO}_{2}+2 \mathrm{H}^{+}+2 e^{-} \\
& 2 \mathrm{Cu}(\mathrm{II})+2 e^{-}=2 \mathrm{Cu}(\mathrm{I}) \\
& 2 \mathrm{Cu}(\mathrm{II})+\mathrm{CO}+\mathrm{H}_{2} \mathrm{O}=2 \mathrm{Cu}(\mathrm{I})+\mathrm{CO}_{2}+2 \mathrm{H}^{+}
\end{aligned}
$$

The CO molecules form part of carbonyl complexes composition, chemical activity of which is notably higher. Thus, in the $\mathrm{Cu}$ (II) $-\mathrm{Cu}$ (I) $\mathrm{Cl}^{--}-\mathrm{CO}-\mathrm{H}_{2} \mathrm{O}$ systems the copper (I) carbonyl complexes serve as a reducer, and the process of $\mathrm{Cu}(\mathrm{II}) \rightarrow \mathrm{Cu}(\mathrm{I})$ reduction is autocatalytic.

In Table 1 the test results of temperature effect on copper (II) reduction to copper (I) in the process of hydrocarbonylation are shown. Solution composition, g/l: $\mathrm{CuSO}_{4}-116.5 ; \mathrm{NiSO}_{4}-63.5$; $\mathrm{NaCl}-40.0 ; \mathrm{H}_{2} \mathrm{SO}_{4}-108$.

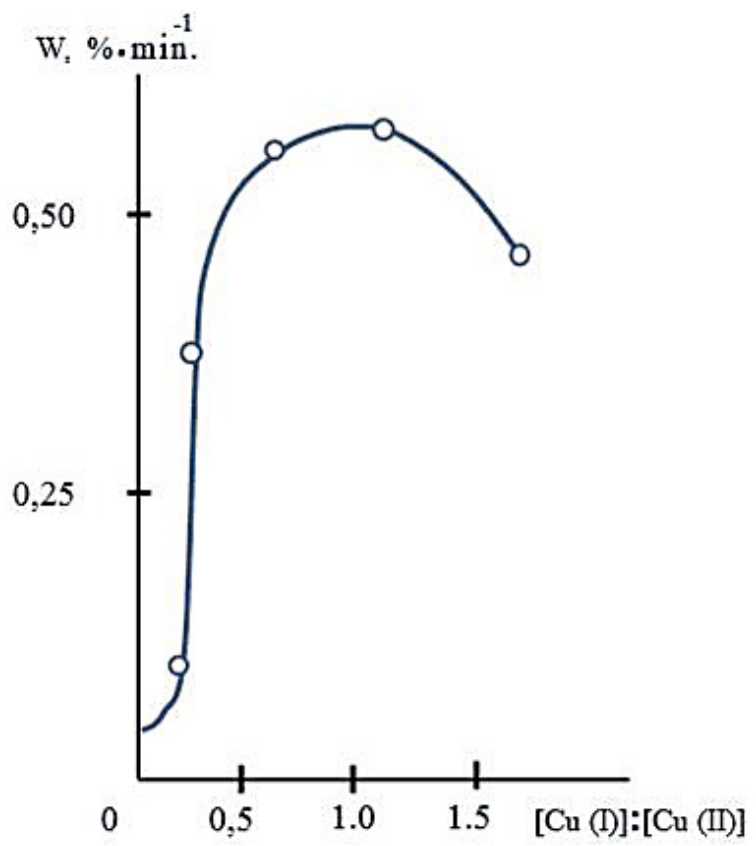

Fig. 2. Relationship between the $\mathrm{Cu}(\mathrm{II}) \rightarrow \mathrm{Cu}(\mathrm{I})$ reduction $(\mathrm{W})$ rate by carbon monoxide and $\mathrm{Cu}(\mathrm{I}): \mathrm{Cu}(\mathrm{II})$ concentration ratio. 


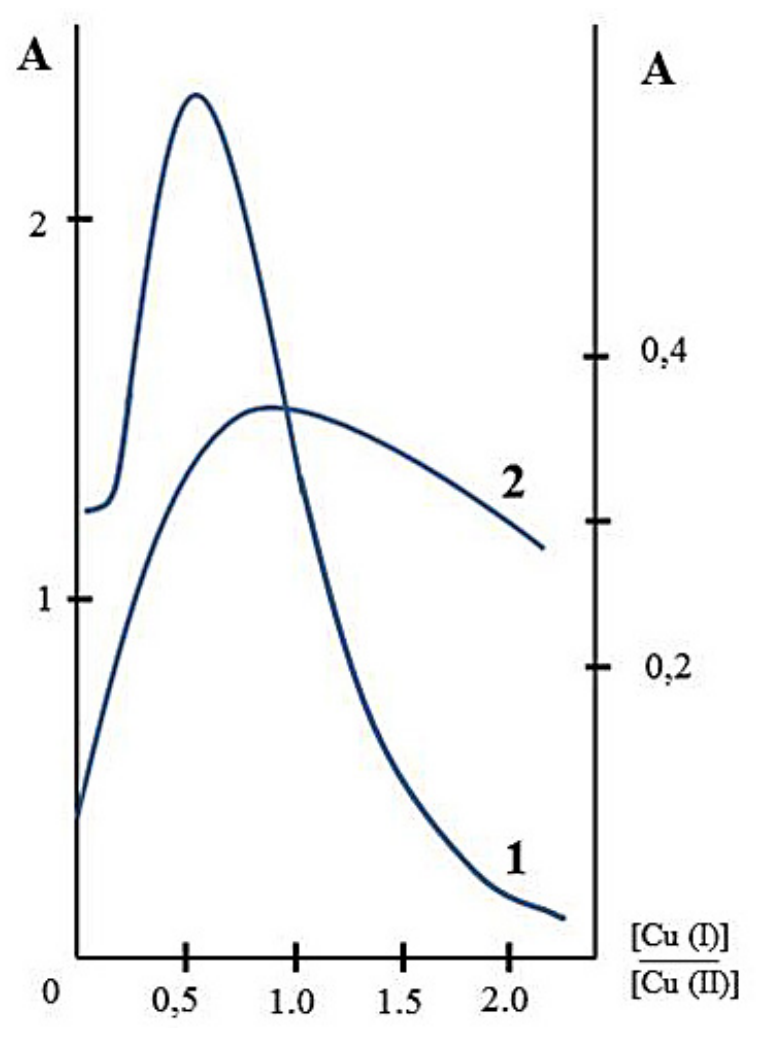

Fig. 3. Absorption (A) change of solutions in the process of $\mathrm{Cu}(\mathrm{II}) \rightarrow \mathrm{Cu}(\mathrm{I})$ reduction by carbon monoxide: $1-\lambda=400 \mathrm{~nm} ; 2-\lambda=490 \mathrm{~nm}$.

Table 1. Relationship between the reduction ratio (W) of $\mathrm{Cu}(\mathrm{II})$ to $\mathrm{Cu}(\mathrm{I})$ and temperature during hydrocarbonylation

\begin{tabular}{|l|l|l|l|l|}
\hline T, oC & 20 & 35 & 50 & 7 \\
\hline W, \%×min-1 & 0.23 & 0.67 & 0.80 & 0.90 \\
\hline
\end{tabular}

The treatment environment was: PCO - atmospheric, $\mathrm{CO}$ consumption is 0.12 litre per 1 litre of solution per minute. $\mathrm{W}=\mathrm{f}(\mathrm{T})$ relationship indicates that the process should be held at $\mathrm{t} \leq 50^{\circ} \mathrm{C}$, because its further increase has no notable effect on reduction ratio that is associated with the decrease of copper (I) carbonyl chloride stability with temperature increase. Besides copper (II), reduction ratio substantially increases along with the specific gas discharge, but at the same time the CO utilization rate decreases. With the carbon monoxide content in process gases at the level of $30 \%$ by volume, the copper reduction rate is $\sim 0.5 \% \mathrm{~min}$.

Important indicators of the hydrocarbonyl process technological capabilities for multicomponent solutions processing to high purity copper, shown in Figure 4, are copper (II) reduction degree to copper (I) and completeness of its deposition. These indicators are determined by the redox potential value in the system of $\mathrm{Cu}(\mathrm{II})$ $\mathrm{Cu}(\mathrm{I})-\mathrm{Cl}^{-}$and chloride ion concentration, and depend on, as shown in our studies, the $\mathrm{Cl}^{-}$: $\mathrm{Cu}(\mathrm{II})$ ratio of molar concentrations in the initial solution. The higher this value is, the greater the copper (II) reduction ratio, but the lower the copper (I) deposition degree.

The test results analysis showed that the use of producer gases permits recovery to sedimentary material of up to $95 \%$ of copper from multicomponent solution in 3 hours at the temperature of $\mathrm{t}=40-50^{\circ} \mathrm{C}$ and the $\left[\mathrm{Cl}^{-}\right]:[\mathrm{Cu}(\mathrm{II})]$ ratio in the initial solution of $\cong 1.5$.

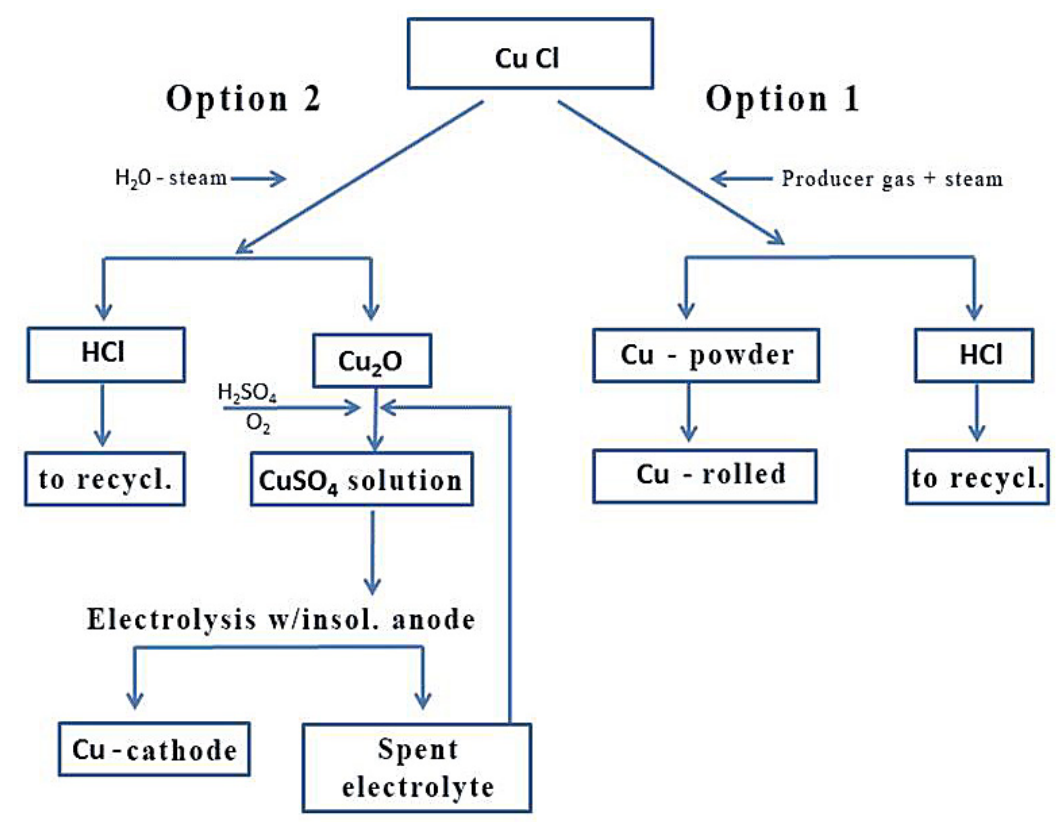

Fig. 4. Schematic diagram of copper (I) chloride to metal processing 


\section{DISCUSSION}

The results of chemical and technological studies of processes, executing in the $\mathrm{Cu}(\mathrm{II})$ $\mathrm{Cu}(\mathrm{I})-\mathrm{Cl}^{-}-\mathrm{CO}-\mathrm{H}_{2} \mathrm{O}$ system, justify the new processing technology of copper-bearing intermediate products multicomponent leaching solutions for high purity copper production in the form of powder or cathodic metal. In this case, only one cheap reagent, one or another carbon monoxide containing producer gas, is used.

The technology is based on a hydrocarbonylation process, consisting in the initial solution treatment by producer gas at the atmospheric pressure and the temperature of $20-50^{\circ} \mathrm{C}$, which results in the copper settling out in the form of pure salt - copper (I) chloride. The duration of process cycle is cannot exceed 10 hours at low specific power consumption and high purity product copper. High cost-effectiveness of such production is obvious. If necessary, the copper powder can be processed to very high purity cathodic metal.

\section{CONCLUSION}

Copper (I) chloride should be considered as a key intermediate product of the new technological solution of copper concentrates and other intermediate products of multi-component leaching solutions for high purity copper via chemical or electrochemical reduction. If a technological necessity of complete copper removal from the initial solution arises, as in the case of copper-nickel intermediate products processing, the filtrate after the $\mathrm{CuCl}$ isolation can be treated by nickel powder or its sulphide. The initial intermediate product leaching process should be organized in such a way that the molar concentrations ratio of chloride-ions to copper ions in the obtained solution does not exceed 1.5.

\section{REFERENCES}

1. Altushkin I.A., Levin V.V., Sizikov A.V., Korol Yu.A. 2017. Experience of development of porphyry copper type deposits type in the Urals. Zapiski Gornogo Instituta, 228, 641-648.

2. Fedoseev I.V., Maksimov V.V. 2012. The use of hydrocarbonyl process in copper production technology development. Tevetnye Metally (Non-Ferrous Metals), 9, 21-23.

3. Fedoseev I.V., Barkan M.Sh. 2016. Hydrometallurgical processing development of sulphide coppernickel intermediate products. Tcvetnye Metally (Non-Ferrous Metals), 5, 27-31.

4. Haavanlammi L., Karonen J., Rodriges K. 2011. HydroCopper ${ }^{\circledR}$ - Copper production technology development. Tevetnye Metally (Non-Ferrous Metals), 7, 24-26.

5. Khomchenko O.A., Sadovskaia G.I., Bezbrovskii V.L., Smirnov P.V., Tcapakh S.L. 2014. Development and implementation of nickel and cobalt chloride production technology at JSC Kolskaya Mining and Metallurgical Company. Tcvetnye Metally (Non-Ferrous Metals), 9, 81-88.

6. Lundstrom M., Aromma J., Forsen O., et al. 2005. Leaching of chalcopyrite in cupric chloride solution. Hydrometallyrgy, 77, 1-2, 89-95.

7. Mushkatin L.M., Diachenko V.T. 2009. Problems and prospects for the development of Russian metallurgical facilities of JSC "MMC "Norilsk Nickel" company in the period up to 2020. Tcvetnye Metally (Non-Ferrous Metals), 9, 12-17 (in Russian).

8. Schlesinger M.E., King M.J., Sole W.G. 2011. Devenport, Extractive metallurgy of Copper, 5th ed. Oxford, UK.

9. Tcapakh S.L., Lutova L.S., Chetvernin A.Iu. 2012. Copper depositional mechanisms from chloride solutions in the presence of elemental sulphur and reducer. Tcvetnye Metally (Non-Ferrous Metals), 4, 26-31 (in Russian).

10. Valkamak K., Karonen J. 2013. Outotec's chloride based process for production of copper cathode from primary copper sulfide concentrates. Proceeding of Copper, Santiago, Chili, 285-295. 